\title{
Financial Sustainability of Cultural Heritage: A Review of Crowdfunding in Europe
}

\author{
Daniela Angelina Jelinčić *(i) and Marta Šveb \\ Institute for Development and International Relations, 10000 Zagreb, Croatia; marta.sveb@irmo.hr \\ * Correspondence: daniela@irmo.hr
}

Citation: Jelinčić, Daniela Angelina, and Marta Šveb. 2021. Financial Sustainability of Cultural Heritage: A Review of Crowdfunding in Europe. Journal of Risk and Financial Management 14: 101. https:// doi.org/10.3390/jrfm14030101

Academic Editor: Colin Michael Hall

Received: 1 February 2021

Accepted: 26 February 2021

Published: 4 March 2021

Publisher's Note: MDPI stays neutral with regard to jurisdictional claims in published maps and institutional affiliations.

Copyright: (c) 2021 by the authors. Licensee MDPI, Basel, Switzerland. This article is an open access article distributed under the terms and conditions of the Creative Commons Attribution (CC BY) license (https:/ / creativecommons.org/licenses/by/ $4.0 /)$.

\begin{abstract}
Most cultural heritage projects strive in ensuring financial sustainability, mainly relying on public subsidies. At the same time, they lack fund management policies which directly affects their financial sustainability. European Union heritage policies focus on sustainability but after investments have been made, there are rare cases which can boast about it. A number of heritage funding mechanisms exist which are explained in this review paper, while the focus is on crowdfunding as an alternative mechanism. The study used literature review method based on PRISMA guidelines to analyze new trends and suitability of crowdfunding for cultural heritage projects, and to detect possible factors influencing its success. The purpose was to add to the existing knowledge while offering a systematic review which can be applied in practice. Findings indicate the trend of participatory approach to heritage, which is in line with the participatory nature of crowdfunding campaigns. Further, crowdfunding suitability for cultural heritage projects was confirmed while its success factors majorly depend on the policy framework, heritage project nature and management of the campaign itself.
\end{abstract}

Keywords: cultural heritage; financial sustainability; crowdfunding; Europe

\section{Introduction}

The meaning of culture has matured from representing artistic expression with no economic value to becoming a public good and a force of economic change (Manda et al. 2017). However, processes of preservation, protection, regular operating, and maintenance of cultural heritage are expensive and typically require financial resources, which are often difficult to obtain. Therefore, to increase the likelihood of funding, cultural projects need to demonstrate economic and financial sustainability (Eppich and Grinda 2019). Economic sustainability is generally defined as the "process of allocating and protecting scarce resources while ensuring positive social and environmental outcomes" as well as intergenerational equity (i.e., meeting the needs of the present generation without compromising the needs of future generations) (Doane and MacGillivray 2001, p. 16). Therefore, when applied to culture, the economic sustainability of a cultural project refers to the project's ability to accumulate profit for the general economy. Financial sustainability generally imputes the fiscal ability to continue current policies and service delivery after the funding terminates (Subires and Bolivar 2017). In the cultural context, financial sustainability ensures the cultural project will have enough resources to meet all the financial obligations, such as operating and maintenance, even after finance incentives end (Eppich and Grinda 2019). Both economic and financial sustainability are important aspects of cultural project sustainability, but they differ in scope: economic sustainability is a macro concept and refers to the effect the project can have on the economy in general, while financial sustainability is a micro concept which determines whether the project will be sustainable in the long-term. Thus, economic sustainability is related to instrumental cultural values, while financial sustainability refers to the intrinsic values of culture per se ensuring its durability due to the available finances. 
Europe 2020 Strategy put forward the concept of sustainability (European Commission 2010) for all EU funded projects as to ensure "durable effects of regional development" (Jelinčić and Tišma 2020). This also applies to cultural heritage projects which, if applying for EU funding, must demonstrate how sustainability will be ensured. The shameful practice has revealed, however, that cultural heritage projects often fail on that task after the funding ends. Sustainability has different facets (cultural, economic, environmental, and social) which may possibly put weight on cultural heritage managers to balance among all of them. As to ensure economic and financial sustainability, specific managerial knowledge is needed, alongside nurturing creative and innovative approaches to funding. While there are existing studies on financial sustainability of cultural heritage which offer some knowledge on the topic (e.g., Chiesa and Handke 2020; Eppich and Grinda 2019; Zhao and Shneor 2020), ensuring innovative funding practices in cultural heritage is not easy. This is mainly due to a number of different funding mechanism, whose effectiveness and efficiency have so far not been systematically scientifically analyzed. Rather, professional collections on the topic exist (e.g., RESTAURA 2019; Jelinčić and Glivetić 2020; UNITO 2020; Finpiemonte 2021) covering only partial overview of financial instruments and not offering a systematic (and preferably comparative) review. Due to this void, this paper first aims to provide a systematized knowledge on funding mechanisms available for cultural heritage. Since it would be an extremely demanding task to analyze all of the so far existing funding mechanisms, among the detected ones, crowdfunding has been selected for further review as to present the latest developments and trends in crowdfunding cultural heritage in Europe. The goal was to provide knowledge on the latest trends and developments in cultural heritage crowdfunding in Europe, to see its suitability for cultural heritage projects, and to detect possible factors influencing the success of crowdfunding campaigns. The review study revealed the trend of participatory approach to heritage, which is in line with the participatory nature of crowdfunding campaigns. Further, crowdfunding suitability for cultural heritage projects was confirmed while its success factors majorly depending on the policy framework, heritage project nature, and management of the campaign itself.

The structure of the paper is as follows: first, financial sustainability in cultural heritage is explained alongside conditions cultural heritage sites have to fulfil in order to achieve it. Then, an overview of usual cultural heritage funding mechanisms is presented focusing on the crowdfunding. Further, methods used for the review research are explained followed by the underlying concept and trend in cultural heritage management, including funding: participatory approach. Cultural heritage crowdfunding in several reviewed European countries is explained in search for suitability of crowdfunding for cultural heritage projects. Finally, success factors for crowdfunding campaigns are analyzed. Conclusions are drawn at the end in relation to the posed research questions.

\section{Financial Sustainability of Cultural Heritage}

According to Eppich and Grinda (2019), financial sustainability of cultural heritage includes five categories: revenue identification, expenditure analysis, administration and reporting, strategic planning, and alignment and support of the mission. Revenue identification refers to the identification of three types of inputs into the cultural heritage site: pricing (e.g., entry tickets), donating, and subsidizing (the role of government). Expenditure analysis shows where the funds are being spent, while administration and reporting provide insight into how the funds are being spent (e.g., financial condition and cash flow). The fourth category of financial sustainability of cultural heritage, strategic planning, refers to the income and expenditure planning, as well as the risk assessment and taking advantage of the income opportunities. The final and most important category is alignment and support of the mission of the cultural heritage site, which safeguards the cultural site not to become overly commercialized. Their research showed that the majority of cultural heritage sites are not financially sustainable, they overly depend on government subsidizing, and they usually do not have effective fund management policies. For cultural heritage sites to ensure financial sustainability, they should satisfy five specific 
conditions (Eppich and Grinda 2019): (1) they need to have an environment which encourages future financial planning; (2) they should provide education and knowledge about finances; (3) there should be an awareness of financial sustainability benefits which leads to a positive perception of finance; $(4)$ the cultural heritage site has to have autonomy in decision making; and (5) public interest should be a priority through the involvement of the local community.

Cultural heritage site's economic value lays in revenues which are most often derived from cultural tourism, accounting for around $40 \%$ of European tourism (Šebová et al. 2014). However, although higher visitation leads to more revenues and better financial sustainability of tourism, it is not always as beneficial for cultural heritage sites. More tourists do not necessarily lead to more financial sustainability as excessive visitation can often be the cause of overcrowding, environmental damage, and wear-and-tear (Mourato et al. 2004) hence raising the costs of restoration and maintenance. To balance the relationship between culture and tourism and stimulate the financial sustainability of both, Loulanski and Loulanski (2011) emphasize the heritage capital approach, also known as cultural capital (Throsby 1999). The heritage capital approach is advocated as one of the main components of cultural and tourism sustainability development and planning. This approach emphasizes the importance of preservation of cultural values of the heritage site and maintenance of its cultural capital (Loulanski and Loulanski 2011), which in turn stimulate a flow of goods and services that enable income and financial sustainability of cultural heritage and cultural tourism (Throsby 1999). Additional two factors that have shown to be beneficial in creating a balance between culture and tourism are interpretation and pricing. Interpretation can be a viable tool to prevent environmental damage to the cultural heritage site if it is "place-centred, conservation-oriented, and pluralistic" while combining education and entertainment (Loulanski and Loulanski 2011, p. 849), thus also impacting both its economic and financial sustainability. Hence, using interpretation to cultivate awareness and appreciation of cultural heritage in visitors, cultural resources can be preserved. Furthermore, pricing, as a second useful tool, can help lower the risks of overcrowding and hence prevent wear-and-tear as well as improve visitor's experience (Mourato et al. 2004). Raising the prices of a heritage site or changing the prices to satisfy the management objectives can also increase revenues and decrease the dependence on the public funds, hence ensuring financial sustainability.

\subsection{Cultural Heritage Funding Mechanisms: An Overview}

One of the most important cultural management decisions is how to secure funding for cultural projects and from whom. There are four categories of financial funding mechanisms: grants, financial instruments, market revenues, and hybrid instruments (Finpiemonte 2021).

Specifically, grants tend to be unrepayable and may be direct or indirect. Direct grants provide money for specific activities such as the restoration of a cultural heritage site, while indirect grants enable access to financial instruments. For example, the indirect grant can be money used as leverage to obtain debt or even bank loans and to pay an interest rate.

Money obtained through a financial instrument has to be repaid to the investors. There are two categories of financial instruments: debt and equity. Debt assumes a contract between the lender and the borrower under which the money is lent to the borrower and needs to be repaid within a certain time frame, while equity provides total or partial ownership of the firm by the lender while financial return depends on the profitability of the invested cultural project.

Market revenues and fees are acquired through the sale of goods and services, such as accommodation, transport, events, entry fees, rentals, etc.

Finally, hybrid instruments, a mix of different types of financial schemes, represent the optimal financial instrument cultural projects should be aiming for (Finpiemonte 2021) as they are most likely to ensure financial sustainability. This includes a recoverable grant that must be repaid if the project succeeds on previously defined parameters and if the 
loaner earns enough money to repay the investment. If not, the recoverable grant does not have to be repaid and in such a case it is considered a philanthropic gift.

Other examples of hybrid instruments are forgivable loan, which turns into an unrepayable grant if the project is successful, and convertible grant that transforms into equity (i.e., the lender obtains partial or complete ownership of the cultural project if it is successful). Moreover, revenue share agreements are also a frequent hybrid instrument; when used, the lender invests money in the project and receives an agreed percentage of revenues in the future.

All of the beforementioned types of funding can be provided from the public or private sources. Public funding typically does not have to be repaid and is sometimes used to stimulate private funding. Public funding comes in the following forms: (1) grant; (2) combination of a grant and private funding (repayable funding); (3) public procurement; and (4) public budget (Finpiemonte 2021).

Although public funding tends to be an unrepayable grant, nowadays financial instruments that use financial intermediaries (banks, funds, etc.) are becoming more popular and are even replacing grants, as there is a lack of financial resources on the national level. This approach has already been taken in the EU 2014-2020 perspective for the cultural and creative sectors seeking "to change behaviour among some parts of the sector by encouraging a shift from a mentality of grants to loans, strengthening their competitiveness while reducing reliance on public funding" (EUR-Lex 2011). Furthermore, public procurement is another example of public funding which takes the pressure of the national grant budget, as this way there is an exchange of resources: for example, a cultural heritage site is rented for an event which brings revenue. Public budget (EU, national, regional, and local level) is often the main type of funding of cultural heritage sites (Manda et al. 2017) and typically, national governments provide support by assigning a part of the national budget to the cultural sector (Varbanova 2003). Although preserving cultural heritage is a duty of the national governments, the EU has developed several policies and programs with the main goal of safeguarding European heritage to enhance the sense of belonging and communality through common heritage and European identity (Lähdesmäki 2014). Such programs provide direct funding through grants and indirect funding through development of cultural policies or through financial intermediaries (i.e., combination of grants and private funding).

Private funding, which is usually provided by banks, alternative channels (funds, capital market, and crowdfunding), and philanthropic investors (Finpiemonte 2021), has been increasing in its importance. Banks and alternative channels use financial instruments and usually require repayment of the investment, while philanthropic investors provide grants and do not require repayment.

Alternative channels are an interesting option that can "strengthen the ability to access bank credit" (Finpiemonte 2021). This includes fin tech and crowdfunding. Fin tech is an example of peer-to-peer lending, where loans are given through social lending platforms at interest rates lower than those applied by the banks. However, this type of funding can be risky as it is not controlled by intermediaries. Crowdfunding is a well-used and effective method in the cultural sector, which is based on Internet obtained financial incentives from groups of people interested in the subject and can range from simple philanthropic donations to equity crowdfunding (Finpiemonte 2021). On top of that, due to the decrease of national and regional funding, the role of foundations as philanthropic investors, which combine the capital of several investors and invest it in the chosen cultural projects, has become increasingly important (Varbanova 2003).

Recently, innovative financial schemes that combine public and private agreements have been used. Impact finance, an alternative to classical donations, where an investor can invest in cultural projects with predetermined objectives and expected environmental and/or social impact can stimulate public and private partnerships inspired by a real change (Finpiemonte 2021). The public-private partnership (PPP) is a long-term collaboration between public and private entities, where each has its role in project management. 
Through this type of agreement, more resources are secured while the risks are distributed. PPP, when applied to cultural heritage, should also involve local community in the management of the cultural project (RESTAURA 2019).

Public and private investments in cultural heritage and cultural tourism can produce optimal economic returns due to funds typically being used for renovations, maintenance, and new cultural projects with proven ability to attract more visitors, stimulate expenditure, and inspire an environment for job creation. This leads to more revenue, and thus financial and economic sustainability (Nijkamp 2012). Therefore, the type of financial schemes used for cultural heritage and cultural tourism and their efficiency is becoming increasingly important, as the goal of the funding is to eventually secure financial and economic sustainability of culture, with minimal public and/or private expenses.

Further on, we focus on crowdfunding, which is categorized as an alternative funding mechanism and is also used in the cultural heritage sector.

\subsection{Crowdfunding Principles}

Crowdfunding is a novel method used to collect money from a large number of people, by the means of Internet (Shneor et al. 2020). Money is generally collected to support specific projects, for which professional financing is difficult to obtain and where motivation to invest is low. This is common for cultural projects, and especially heritage (Chiesa and Handke 2020). It is no surprise then that one of the first crowdfunding platforms (ArtistShare) was specialized in cultural sector, while culture today remains one of the main areas of crowdfunding application (Rykkja et al. 2020). Although such collective funding of cultural heritage has a long history, as even the Statue of Liberty was funded through calls for donations through newspapers, nowadays the term "crowdfunding" generally refers to funding through online platforms (Chiesa and Handke 2020). Through crowdfunding and the use of digital platforms, "fundraising activities become worldwide available" instead of being bounded by geographical location of the project (Roy 2020, p. 179). This has become increasingly important, as cultural organizations are facing cuts in public funding and there is large competition for sponsors and donations, which has adverse effects on consumption of cultural expression and heritage (Rykkja et al. 2020).

The main parties involved in transactions are the fundraiser, the backer, and the platform. Fundraiser makes a public call, using a chosen platform for the financing of a specific project, while the backer is someone who answers the call by providing financial resources. Typically, platforms make revenue from campaign success fees (Shneor et al. 2020), they keep about $5-15 \%$ of the amount collected by the fundraiser (Chiesa and Handke 2020). There are four types of crowdfunding models: (1) crowdlending, when backers provide loans to fundraiser and expect repayment with interest; (2) equity crowdfunding, when backers obtain a percentage of ownership of an organization/project they are backing; (3) reward crowdfunding, when backers receive non-monetary rewards for their financial help; and (4) donation crowdfunding, when backers provide financial resources out of philanthropic reasons with no expectation of any type of return. The first two models are investment models, while reward and donation are non-investment models (Shneor et al. 2020). Out of these four models, crowdlending is the most common type of crowdfunding in the world (Roy 2020), while reward crowdfunding is popular in cultural projects with $88 \%$ of cultural campaigns using this model (Chiesa and Handke 2020; Rykkja et al. 2020).

Adamo et al. (2020) explain there are two collection models which are typically used. The first model "all or nothing", implies that if the target of the campaign is not achieved, the whole sum needs to be returned to the backers of the campaign, while the second model "keep it all" enables the fundraiser to keep the money even if the objective is not reached. It is the fundraiser's choice which model to use.

According to Shneor et al. (2020), crowdfunding process consists of seven stages which occur in the pre-campaign, during the campaign and in the post-campaign. Planning, creation, and review are preparatory activities which occur in the pre-campaign, management and results occur when the campaign is being executed on the chosen plat- 
form, while delivery and mobilization help establish a relationship with the backers in the post-campaign. Each of these stages is explained in more detail in Table 1.

Table 1. The crowdfunding campaign process.

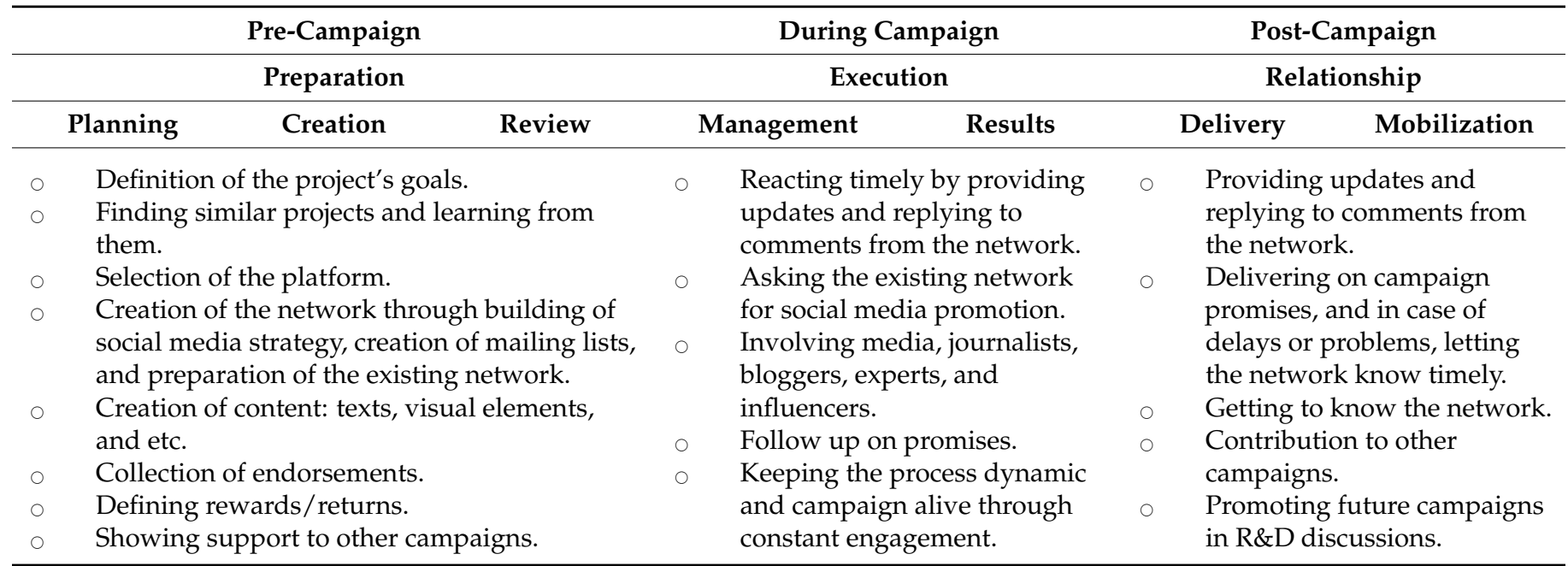

Source: Shneor et al. (2020), slightly adapted by the authors.

As mentioned, crowdfunding has been categorized as an alternative method and is usually based on a one-time campaign and is thus usually used in obtaining the seed money for the project. However, according to the Shneor et al. (2020) model presented above, maintaining relationships with the backers may have impact on sustainability. A further review of the latest knowledge on cultural heritage crowdfunding was researched and presented below.

\section{Materials and Methods}

As sustainability of cultural heritage projects is in the focus of European Union policies, and it justifies the EU investments in this sector, often alternative funding mechanisms are sought. They can support projects even after the EU funding ends. Along this line, there is an increasing interest in crowdfunding in the cultural heritage sector. However, cultural heritage managers are still hesitant to apply this mechanism due to their lack of knowledge on the topic or to the uncertainty of success. A systematic review of the selected academic and professional resources has been carried out with the aim to present latest developments and trends in crowdfunding of cultural heritage in Europe thus adding to the existent knowledge on the topic.

The following research questions were posed:

(1) What are the latest trends and developments in crowdfunding for cultural heritage in Europe?

(2) Is crowdfunding a suitable funding mechanism for cultural heritage projects?

(3) What factors influence the success of crowdfunding campaigns?

Answers to these questions could enhance the application of crowdfunding mechanism in the cultural heritage sector, thus adding to sustainability of individual projects.

\subsection{Information Sources and Eligibility Criteria}

Extensive research of the Google Scholar database was conducted throughout December 2020. Google Scholar has been selected as it includes wide research across Internet in its search results, which greatly expanded our analysis of the highly narrow and (still) relatively unresearched topic of crowdfunding cultural heritage in Europe. We wanted to obtain as many academic papers available on the selected topic, but the screening narrowed down the results to peer reviewed journal articles, book chapters, reports, one Ph.D. thesis, and one M.Sc. thesis reporting on the crowdfunding and cultural heritage in Europe, and 
these were included in the analysis. A Boolean approach was used, and the following search terms were applied ("crowdfunding") AND ("cultural heritage") AND ("Europe"). In order to decrease the number of irrelevant articles, we excluded patents and citations.

Records published in English in the year 2020 were eligible for inclusion as we wanted to see the latest developments on the topic. Geographical scope of the research focused on Europe since the starting point of the research was Europe 2020 Strategy which insisted on sustainability of the projects.

Our search found 237 results.

\subsection{Study Selection}

The study selection process is illustrated in Figure 1.

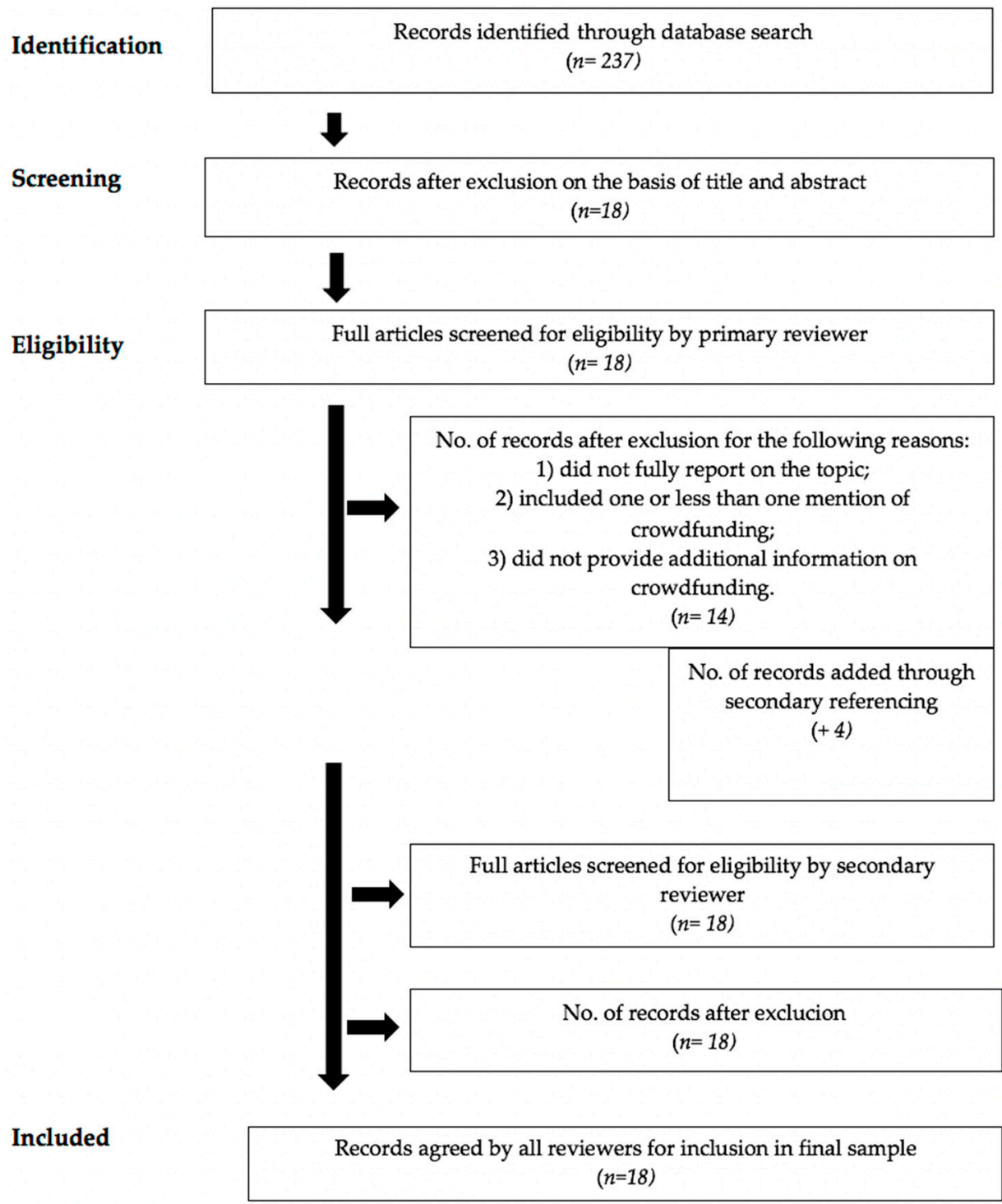

Figure 1. PRISMA flow diagram—schematic view of search strategy.

In the first stage of screening, papers were excluded based on their title and abstract, if they did not clearly report on crowdfunding of cultural heritage in Europe. However, we decided to include some papers which dealt with crowdfunding, although they did not specifically discuss cultural heritage (we explain this later). Papers were excluded on the basis of title and abstract if they were 
- entirely unrelated to the topic of crowdfunding of cultural heritage in Europe or crowdfunding in general;

- not reporting on crowdfunding of cultural heritage;

- or reporting on crowdfunding of cultural heritage, but not in Europe.

Full-text files were obtained for the remaining records.

At this stage, we included papers if they:

- fully reported on the topic of our interest;

- if they included more than one mention when we searched "crowdfunding" within the text;

- if they provided additional information on crowdfunding not found in the papers that fully reported on the topic of our interest;

- if they were useful secondary references: if there was "crowdfunding" mentioned only in the citations of the paper from our search, we checked the reference to see whether that cited paper might report on the cultural heritage crowdfunding in Europe.

At the end of this stage, we had 18 academic papers which were included in our analysis.

All final sample papers were assessed by a second reviewer to reduce the risk of inclusion bias.

\section{Participatory Approach as the Underlying Crowdfunding Mechanism}

Faro convention is a treaty, signed in Portugal in 2005, by which European states agreed to protect cultural heritage and citizens' right to engage and participate in that heritage. Through this treaty, governments recognize the importance of communities in cultural heritage valorization and promote culture as a common good which is shared among society. Hence, the treaty encourages participatory governance of cultural heritage in which multiple stakeholders are involved, including the government, professionals, non-governmental organizations, the voluntary sector, and local and national civil society (Kontiza et al. 2020). The value of cultural heritage remains central and it is what essentially motivates individuals and organizations to engage and protect the cultural heritage. Participation of multiple stakeholders and recognition of cultural heritage as a common good, may lead to better and more sustainable management of cultural heritage, which can eventually lead to (financial) sustainability of the local community. Crowdfunding, as a funding method which is based on the involvement of various organizations and/or individuals, is an example of the participatory approach which enables not only local, but global community to get involved in the valorization and protection of the common cultural heritage. On top of that, a hybrid model called match-funding has been used to stimulate financing from the public and private organizations. It is a type of crowdfunding in which multiple stakeholders are involved and each donation is complemented by the funds from public and/or private organizations which enhances project's success and enables a higher amount of donations overall (Morell et al. 2020). Moreover, crowdfunding inherently relies on the interest of the organizations and individuals to donate/invest in a specific cultural heritage project which, in a sense, is valorization itself-if people are willing to donate or invest, it shows that they recognize the value of the specific heritage and want to protect it for the future generations, thus promoting its sustainability.

The process of value co-creation and enhanced community participation enables consumers to engage in the production of the product they eventually want to consume, which leads to feelings of empowerment (Massi and D'Angelo 2020). For example, Rekrei project with a global scope, focused on reproduction of the damaged or destroyed cultural heritage, enables users to actively participate through uploading images of destroyed heritage and by providing financial donations for the project, which are believed to empower and involve users even further. Rekrei project obtains its resources from multiple stakeholders through crowdfunding, which is considered a bottom-up process that "guarantees economic sustainability" (Massi and D'Angelo 2020, p. 121). 
Furthermore, participation through crowdfunding enables society to choose what remains a cultural heritage and what may become one. It is the society's characteristics and interests that fuel the crowdfunding campaigns and thus have the potential to select new cultural heritage. This is especially applicable to emerging heritage such as digital games (Nylund 2020). Finally, participatory approach leads to "greater public value (Scott 2016), builds new audiences (Brown et al. 2011), enhances self-reliance and awareness (Aas et al. 2015) and leads to consensus and shared sense of ownership (Araujo and Bramwell 1999)" (cited in Nylund 2020, p. 56).

\section{Crowdfunding in Europe: Suitability for Cultural Heritage Projects}

In Europe, but also across the world, cultural heritage organizations are starting to "refashion" themselves by using new media in order to raise funds for their projects. Such organizations are seeing beyond the financial benefits of crowdfunding over Internet, and enjoying the additional perks, such as in case of museums, and higher involvement with museum collections (Oomen and Aroyo 2011). Both small as well as large famous museums engage in crowdfunding, e.g., The Louvre organized a crowdfunding campaign in order to fund a Renaissance painting by Lucas Cranach the Elder. They managed to collect a million euros, from altogether 5000 donors (Oomen and Aroyo 2011).

Formal and informal institutional characteristics are known to influence investment behavior and crowdfunding. Di Pietro and Butticè (2020) conducted a study which analyzed the influence of such characteristics on the crowdfunding development across 27 countries. Their results showed that individualistic countries compared to collectivistic ones show more crowdfunding involvement (informal characteristics). The authors attribute this trend to fewer possibilities of informal interactions between fundraisers and backers which characterizes online crowdfunding, and this is believed to attract individualistic societies, but discourage collectivistic. In the sense of formal characteristics, crowdfunding is more prevalent in countries that have business-friendly legal environment and developed economy, and it is larger in countries with higher uncertainty avoidance, while both crowdlending and equity crowdfunding are popular in countries characterized by long-term orientation (i.e., societies that do not expect immediate gratification, because relatively long time needs to pass for investors to get a financial return for their investments).

On top of formal and informal institutional country-level characteristics, other global factors could also promote or hinder crowdfunding efforts. For example, Covid-19 pandemic has forced people to move from the traditional ways of functioning "offline" and towards the usage of digital technology for interaction, buying goods, and even food delivery (Bahre et al. 2020). Hence, as people are more adapt to digital technologies, cultural heritage could use this opportunity and opt more often for online funding through crowdfunding.

Reviewed papers analyzed several European cases of cultural heritage crowdfunding as to report on the suitability of this funding mechanism for cultural heritage projects. Namely, cases from Finland, Italy, and France have been detected.

\subsection{Finland}

Finish Museum of Games (FMG) is an example of a successful crowdfunding campaign in Europe. Although its main goal was not to raise funds but rather to promote the museum and show a need for the establishment of the game museum, a reward-based crowdfunding campaign on a Finish platform focused on the culture, Mesenaatti.me, raised $€ 85,860$ over six months from more than 1000 donors. As a reward, donors got tickets, t-shirts, invitations to VIP events, etc. (Suominen et al. 2018).

Digital games are still in the process of becoming a cultural heritage; hence, they can be defined as an emerging heritage. Suominen et al. (2018) suggest that for such an emerging heritage, it is more difficult to obtain funding (and crowdfunding) because the cultural community who could appreciate it is still developing. On the other hand, museums which exhibit cultural heritage that has a well-developed community (e.g., paintings, 
sculptures, etc.), are expected to have an easier access to crowdfunding and thus raise more money. Other authors, such as Rykkja et al. (2020), suggest that it is exactly this originality (of game heritage) which might offer better market opportunities. Needless to say, not all crowdfunding campaigns are a success. For example, the Kickstarter has a success rate of up to $36 \%$. Therefore, instead of defining success solely based on collected funds, emerging heritage, and cultural heritage in general could focus on the other benefits such as promotion and community development, which might be even more important (Suominen et al. 2018).

\subsection{Italy}

Because of the Italian bureaucracy system and high level of digital illiteracy, crowdfunding appeared in Italy in 2005, sometime after it started to be used in the other countries (Adamo et al. 2020). Today, crowdfunding is a famous method of funding Italian culture and arts. This is because Italy is known for its rich heritage: churches, monuments, and museums so people across the world are motivated to fund the campaigns in order to preserve such great cultural heritage (Bertasini 2020). Crowdfunding in Italy shows several trends: (1) loyalty, backers have become loyal to organizations instead of projects; (2) decentralization, platforms have become easier to use; (3) internalization, Italian platforms are becoming equally good as large international platforms; and (4) complementarity, crowdfunding has been used by non-profit organizations as well as profit oriented organizations (Adamo et al. 2020).

In Italy, crowdlending and equity-based crowdfunding are the most used types of crowdfunding while the majority of platforms is donation and reward based (Adamo et al. 2020). Furthermore, the most successful campaigns organized by startups involved in arts and cultural heritage, concern those that produce interactive guides to increase the visitor's museum experience (Bertasini 2020).

Compared to other European and world countries, crowdfunding seems to be the most regulated in Italy because the goal of the legislative framework was to encourage organizations to use alternative methods of funding, and thus enhance economic sustainability (Adamo et al. 2020). However, crowdfunding is a very uncertain method of funding. According to Adamo et al. (2020), fundraisers are highly uncertain of the campaign's success at the beginning of their calls, as they are not able to predict whether there will be an interest from the public to support their projects. Low interest to invest is typically associated with cultural projects, that usually do not lead to large revenues (Chiesa and Handke 2020). Thus, crowdfunding should be viewed as a supplementary, rather than alternative method of financing in order to avoid high uncertainty of the funding success (Adamo et al. 2020).

\subsection{France}

France, as one of the cultural leaders, invests $2.6 \%$ GDP on average in culture compared to other European countries that invest around 2.3\%. French cultural heritage has received an envying financial support from public and private entities because of the international prestige of its museums, desire to preserve that heritage, cultural education, as well as generation of economic wealth through attraction of tourists (Pauget et al. 2020). France has three museums in the world's top 10 art museums in terms of attendance (the Louvre Museum, the Pompidou Center, and the Musée d'Orsay), which attract millions of tourists per year, and thus promote local economy development. These museums, as well as other French museums, have three characteristics in common. First, the total number of visitors has been stagnating since 2010. Second, there is a polarization of attendance to famous museums which receive more than $40 \%$ of visitors. The Louvre alone attracts more than 10 million visitors each year. Thus, less famous museums receive much less visitors. Third, there is a decrease in museum subsidies because of the economic crisis (due to COVID-19). 
Because of these reasons, Pauget, Tobelem, and Bootz (Pauget et al. 2020) interviewed experts and produced three possible scenarios of French museum future in 2030. The most feasible of them suggests that museums are turning into "hybrid local institutions" that are self-sustainable through increased funding from non-governmental sources, such as crowdfunding, as well as using the museum resources (e.g., expertise and collections) "to imagine institutions combining culture, health, social, collaborative economy, and the participation of inhabitants". A trend towards participatory approach to heritage is again confirmed here.

\section{Determining the Success of Cultural Heritage Crowdfunding}

The success of cultural heritage crowdfunding campaign is determined by the fundraiser, the backer, the campaign, and the platform (Roy 2020), and is measured by the amount of collected money or by whether campaign goals were achieved (Chiesa and Handke 2020).

The fundraiser is responsible for creating a fundraising campaign which is based on explicit communication, through texts, images, or videos, about the necessary funding, project outcomes and risks, schedule, and fund allocation. Accurate and effective communication with backers, as one of the most important factors for the success of crowdfunding campaign, leads to a perception of project quality and builds trust in backers, which increases the chances of financial backing (Roy 2020). Some studies have shown that fundraisers who used videos to communicate information about the campaign, were more successful than those who did not (Zhao and Shneor 2020). Furthermore, when using reward crowdfunding, the fundraiser needs to specify what type of rewards will be awarded upon completion of the project as well as how the funds will be used if the project goes unplanned. If a project uses equity crowdfunding, the fundraiser needs to communicate the minimum possible investment and the respective share of the project the organization offers (Roy 2020). Therefore, the fundraiser's linguistic style is of paramount importance for the success of the crowdfunding campaign. More specifically, linguistic style using verbal references to intrinsic motivation (e.g., clear explanation of the importance of the project for the community) increases the chances of funding (Chiesa and Handke 2020). Other than that, the fundraiser's social status may help with the success of the campaign-the larger the social network, the higher the reply to the crowdfunding calls (Zhao and Shneor 2020). Moreover, some studies have shown that female fundraisers have relatively better chances of securing funding (Chiesa and Handke 2020; Zhao and Shneor 2020).

The backer, an individual who is willing to fund a project, can be motivated by various factors including obtaining an organization/project share such as in equity crowdfunding, or to obtain a "hedonic pleasure" from funding a project which might bring social and environmental benefits as in the donation crowdfunding (Roy 2020, p. 182). Their personality, norms, geographical distance, as well as cultural distance determine their involvement in the campaign. If the cultural project is something of interest to them, if it is geographically close and culturally similar, they are more likely to invest or donate money (Roy 2020). Zhao and Shneor (2020) use self-determination theory (SDT) developed by Ryan and Deci in 2000, to explain the motivational background of crowdfunding. According to this theory of motivation, behavior is motivated either by intrinsic or extrinsic factors. Intrinsic motivation occurs when the individual inherently enjoys the activity or when the activity has some inherent meaning for the individual, which brings out the feelings of empathy, nostalgia, or sympathy. Consequently, being involved in the activity, such as crowdfunding, enhances positive emotions in the individual. On the other hand, extrinsic motivation occurs when the individual is motivated by external factors such as monetary rewards or recognition (Zhao and Shneor 2020). Hence, based on this theory we could conclude that intrinsic motivation motivates donation-based crowdfunding, while extrinsic motivation, at least to some degree, lays behind crowdlending, equity, and reward crowdfunding, as all of these modes of crowdfunding provide some type of external reward. Therefore, the backers of cultural heritage campaigns involved in donation-based crowdfunding seem to 
be intrinsically motivated, as such projects typically do not entail monetary rewards. Those individuals tend to appreciate the public-good attributes of cultural heritage and are aware of the positive effect cultural projects could have for the community (Chiesa and Handke 2020). Finally, some studies have shown that backers are more likely to get involved in the cultural heritage crowdfunding campaign if the campaign is donation-based and focused on the intrinsic motivation factors (Marchegiani 2018).

The campaign needs to provide a description of the cultural heritage project for which the funds are being collected, required financing, and duration of the campaign. It should also include a number of pledges, however too many pledges can have adverse effects on the campaign (Roy 2020). The popularity of a project theme directly affects the campaign success (Van Montfort et al. 2021). Further, the study conducted by Calic and Mosakowski (2016) showed that cultural projects which were sustainability oriented, had greater funding success on the reward-based crowdfunding platforms such as Kickstarter than those that did not have social orientation.

The platform offers an environment where the campaign can be presented and seen by the backers. Therefore, the more reach the platform has, the higher the chances of financial backing (Chiesa and Handke 2020). Usage of such Internet platforms in cultural heritage to collect money from a large number of individuals has demonstrated to be beneficial, as it significantly reduces coordination and transaction costs which typically accompany the regular "offline" fundraising activities (Zhao and Shneor 2020). Furthermore, crowdfunding of cultural heritage does not bring solely financial benefits, but it also helps with promotion and audience development and engagement (Rykkja et al. 2020), as well as with the promotion of the touristic destination where the heritage is located (Lemmi 2020). Some of the most famous platforms for crowdfunding of cultural heritage and culture in general are ArtistShare, Kickstarter, and Indiegogo (Chiesa and Handke 2020).

Summary of the crowdfunding campaign success factors are presented in Table 2.

Table 2. The crowdfunding campaign success factors.

\begin{tabular}{|c|c|c|c|c|}
\hline Policy-Related & Fundraiser-Related & Backer-Related & $\begin{array}{l}\text { Campaign and } \\
\text { Platform-Related }\end{array}$ & $\begin{array}{c}\text { Heritage } \\
\text { Project-Related }\end{array}$ \\
\hline $\begin{array}{l}\text { Individualistic } \\
\text { orientation }\end{array}$ & $\begin{array}{c}\text { Effective } \\
\text { communication with } \\
\text { backers }\end{array}$ & $\begin{array}{l}\text { Strong intrinsic } \\
\text { motivation }\end{array}$ & $\begin{array}{l}\text { Required campaign } \\
\text { elements: clear } \\
\text { description of the project, } \\
\text { required financing, } \\
\text { campaign duration, } \\
\text { reasonable no. of pledges }\end{array}$ & Popularity of a theme \\
\hline $\begin{array}{c}\text { Enabling } \\
\text { business-friendly } \\
\text { legislative framework }\end{array}$ & $\begin{array}{l}\text { Linguistic style } \\
\text { impacting backers' } \\
\text { intrinsic motivation }\end{array}$ & $\begin{array}{l}\text { Strong extrinsic } \\
\text { motivation }\end{array}$ & $\begin{array}{l}\text { Large reach of the } \\
\text { platform }\end{array}$ & $\begin{array}{c}\text { Sustainable nature of } \\
\text { the project }\end{array}$ \\
\hline $\begin{array}{c}\text { Developed economy } \\
\text { and higher uncertainty } \\
\text { avoidance }\end{array}$ & $\begin{array}{l}\text { Strong networking } \\
\text { abilities }\end{array}$ & & & \\
\hline Long-term orientation & & & & \\
\hline
\end{tabular}

Source: authors' elaboration based on different studies.

\section{Conclusions}

This review research is grounded in the Eppich and Grinda's (2019) work which claims the lack of financial sustainability for the most cultural heritage sites, their prevailing public subsidies and lack of fund management policies. Among different funding mechanisms available for cultural heritage projects, crowdfunding, theoretically categorized as an alternative funding method was further analyzed. As much as a comparative review of different cultural heritage funding mechanisms would add to the body of knowledge related to their adequacy and efficiency, it is extremely challenging as it is extremely related 
to the heritage typology, nature of projects, and context. Thus, it remains a methodological challenge for research in future studies.

At the moment, individual cultural heritage funding mechanisms are reviewed, as is the case with this one. It was concluded that participatory approach to cultural heritage management which is recently strongly accentuated and advocated since it ensures a sense of ownership over the heritage resources, matches the participatory approach in heritage funding. Specifically, crowdfunding represents participation of the backers in funding a specific cultural heritage project, thus standing out as the latest trend. This trend has been specifically estimated for the future of cultural heritage in France. However, as it does not offer high levels of certainty influencing the funding success, it is rather categorized as a supplementary, and not an alternative method, when applied in cultural heritage sector.

Crowdfunding is affected by country-level and global-level characteristics. Specifically, individualistic countries and those that have business friendly economy and higher uncertainty avoidance tend to be more involved in crowdfunding than collectivistic countries. Global factors such as pandemics can also support or hinder crowdfunding efforts.

Results of the analysis in the reviewed European countries showed that crowdfunding is a suitable mechanism for cultural heritage projects. In Finland, a successful campaign has been detected in the sector of emerging heritage (Finish Museum of Games), whereas in Italy and France in the standard cultural heritage sector. However, contradictory opinions have been suggested on the suitability of crowdfunding for cultural heritage projects on the opposed sides (emerging vs. standard): while both the Finnish and the Italian case confirm that branded cultural heritage is more likely to succeed in crowdfunding campaign as it stirs backers' motivation, there are also other authors (Rykkja et al. 2020) suggesting that emerging heritage, due to its originality might also offer competitive advantage over the standard cultural heritage projects. It can also be backed by Bertasini's (2020) findings that crowdfunding campaigns had the greatest success in projects related to interactive guides increasing museum experiences which also represent novel and original aspects of heritage management. Thus, no unanimous conclusions can be drawn on the suitability of crowdfunding for specific type of cultural heritage projects. Future empirical studies may add to new knowledge in that respect. However, this shows that crowdfunding works well with cultural heritage projects in general, regardless of the type, either emerging or standard.

Some other factors, though, may influence crowdfunding campaign success; e.g., in Italy, the importance of legislative framework which regulated crowdfunding in order to entice cultural institutions/organizations has been found. Pertaining to the campaign itself, a prerequisite for success is the inclusion of basic and clearly described campaign elements: project description, required financing, campaign duration, and reasonable number of pledges. Further on, success factors are found in the accurate and effective communication with backers and specific fundraiser's linguistic style which touches on the backers' intrinsic motivation (especially linked with public benefit). Apart from that, success of a crowdfunding campaign is directly linked with the fundraiser's ability to network since larger social networks ensure higher crowdfunding response calls (Zhao and Shneor 2020). Following the same analogy, the larger reach of the platform, the greater chances of crowdfunding backing (Chiesa and Handke 2020). Both intrinsic and extrinsic motivation of the backer has impact on crowdfunding campaigns. Fundraisers may thus seek to elicit sympathy and empathy in order to stimulate bakers' intrinsic motivation for the donation-based type of crowdfunding or to offer different awards to entice extrinsic motivation. Additionally, sustainable nature of projects is a success factor in the rewardbased crowdfunding. Conclusively, provided that the crowdfunding campaign contains the basic necessary elements (project description, required financing, campaign duration, reasonable number of pledges), importance of an enabling policy framework, heritage project nature and management of the campaign itself also determine its success. Campaign management does not depend on the fundraiser's skills only but are related to the backer 
and the platform itself. Additionally, crowdfunding campaign success is enhanced if it is backed by match-funding.

Finally, a reflection also has to be made on the specific nature of cultural heritage projects and their intrinsic value. Thus, in most cases crowdfunding is seen as an alternative or supplementary funding scheme, whereas in cultural heritage projects it may equally work to raise heritage awareness as well as for audience development, as demonstrated by the Finnish Game Museum. It may especially be important in present times when heritage (and art) sector is struggling for audience. Loyalty of backers to organizations instead of projects confirmed in Italy, thus finds additional backing so crowdfunding campaigns may efficiently be used for long-term audience development and deepening their relationship with heritage institutions/organizations. Since COVID-19 pandemic shifted the cultural sector in the digital environment, new opportunities rise in the use of crowdfunding on digital platforms. Alongside, tourism attractiveness of a heritage site might be used in digital marketing, as it increases the success of crowdfunding campaign.

Some limitations of this review study are seen in the time-span and geographical area of the study. As mentioned, the study included only the analysis of papers published in 2020 with the rationale of detecting the latest trends in crowdfunding. Some earlier papers though might also be useful in this respect. In the same way, the goal here was to analyze cultural heritage in Europe, but a larger geographical might offer some answers to the research questions, especially those pertaining to the crowdfunding success factors. Future research might extent in those directions.

Author Contributions: Conceptualization, D.A.J. and M.Š.; methodology, M.Š.; validation, D.A.J.; formal analysis, M.Š.; investigation, X.X.; resources, M.Š.; writing—original draft preparation, M.Š.; writing-review and editing, D.A.J.; visualization, M.Š. and D.A.J.; supervision, D.A.J.; project administration, D.A.J.; funding acquisition, D.A.J. All authors have read and agreed to the published version of the manuscript.

Funding: This research is an indirect output of a larger project "ForHeritage: Excellence for integrated heritage management in central Europe" funded by the EU Interreg Central Europe Programme, grant number CE1649.

Institutional Review Board Statement: Not applicable.

Informed Consent Statement: Not applicable.

Data Availability Statement: No new data were created or analyzed in this study. Data sharing is not applicable to this article.

Conflicts of Interest: The authors declare no conflict of interest.

\section{References}

Adamo, Rosa, Domenica Federico, Mariantonietta Intonti, Simona Mele, and Antonella Notte. 2020. Crowdfunding: The case of Italy. In Banking and Finance. Edited by Razali Haron, Maizaitulaidawati Md Husin and Michael Murg. London: IntechOpen.

Bahre, Heike, Giovanni Buono, and Valerie Isabel Elss. 2020. Innovation embraces Tradition-The Technology Impact on Interpretation of Cultural Heritage. LUMEN Proceedings 13: 319-26. [CrossRef]

Bertasini, Matteo. 2020. Startups Value Proposition in the Tourism and Art Sector: An Empirical Analysis of Digital and Innovative Trends. Master's thesis, Polytechnic University of Milan, Milan, Italy.

Calic, Goran, and Elaine Mosakowski. 2016. Kicking off social entrepreneurship: How a sustainability orientation influences crowdfunding success. Journal of Management Studies 53: 738-67. [CrossRef]

Chiesa, Carolina Dalla, and Christian Handke. 2020. Crowdfunding. In the Handbook of Cultural Economics. Edited by Ruth Towse and Trilce Navarrete Hernández. Cheltenham: Edward Elgar Publishing, pp. 158-67.

Di Pietro, Francesca, and Vincenzo Butticè. 2020. Institutional characteristics and the development of crowdfunding across countries. International Review of Financial Analysis 71: 101-543. [CrossRef]

Doane, Deborah, and Alex MacGillivray. 2001. Economic sustainability: The business of staying in business. New Economics Foundation. New Economics Foundation. Available online: https://www.dphu.org/uploads/attachements/books/books_5735 _0.pdf (accessed on 28 January 2021).

Eppich, Rand, and José Luis García Grinda. 2019. Sustainable financial management of tangible cultural heritage sites. Journal of Cultural Heritage Management and Sustainable Development 9: 282-99. [CrossRef] 
EUR-Lex. 2011. Creative Europe-A New Framework Programme for the Cultural and Creative Sectors (2014-2020). In Communication from the Commission to the European Parliament, the Council, the European Economic and Social Committee and the Committee of the Regions. Available online: https:/ / eur-lex.europa.eu/legal-content/EN/TXT/HTML/?uri=CELEX:52011DC0786\&from= SL (accessed on 28 January 2021).

European Commission. 2010. Europe 2020: A Strategy for Smart, Sustainable and Inclusive Growth. Communication from the Commission. Available online: http:/ / eur-lex.europa.eu/LexUriServ/LexUriServ.do?uri=COM:2010:2020:FIN:EN:PDF (accessed on 3 February 2020).

Finpiemonte. 2021. Financial Instruments and Innovative Financial Schemes for Cultural Heritage. INTERREG Europe Project, Financed by the European Regional Development Fund. Available online: https: / www.interregentral.eu/Content.Node/02.Financial-schemes.pdf (accessed on 28 January 2021).

Jelinčić, Daniela Angelina, and Dragana Glivetić. 2020. Cultural Heritage and Sustainability. INTERREG Europe Project, Financed by the European Regional Development Fund. Available online: https://www.interregeurope.eu/fileadmin/user_upload/tx_ tevprojects/library/file_1586942702.pdf (accessed on 28 January 2021).

Jelinčić, Daniela Angelina, and Sanja Tišma. 2020. Ensuring sustainability of cultural heritage through effective public policies. Urbani Izziv/Urban Challenge 31: 78-87. [CrossRef]

Kontiza, Kalliopi, Angeliki Antoniou, Abdullah Daif, Susana Reboreda-Morillo, Maddalena Bassani, Silvia González-Soutelo, Ioanna Lykourentzou, Catherine Emma Jones, Joseph Padfield, and Martín López-Nores. 2020. On How Technology-Powered Storytelling Can Contribute to Cultural Heritage Sustainability across Multiple Venues-Evidence from the CrossCult H2020 Project. Sustainability 12: 1666. [CrossRef]

Lähdesmäki, Tuuli. 2014. The EU'S Explicit and Implicit Heritage Politics. European Societies 16: 401-21. [CrossRef]

Lemmi, Enrica. 2020. Heritage and new communication technologies: Development perspectives on the basis of the Via Francigena experience. Paper presented at Heritage, Tourism, and Hospitality International Conference, Mendrisio, Switzerland, April 6-8.

Loulanski, Tolina, and Vesselin Loulanski. 2011. The sustainable integration of cultural heritage and tourism: A meta-study. Journal of Sustainable Tourism 19: 837-62. [CrossRef]

Manda, Cezar Corneliu, Cristina Elena Nicolescu, and Dana Mortelmans. 2017. Financing culture institutions in european context. SEA: Practical Application of Science 5: 179-85.

Marchegiani, Lucia. 2018. From Mecenatism to crowdfunding: Engagement and identification in cultural-creative projects. Journal of Heritage Tourism 13: 143-51. [CrossRef]

Massi, Marta, and Alfredo D’Angelo. 2020. Reversing Heritage Destruction through Digital Technology: The Rekrei Project. In Rediscovering Heritage Through Technology. Edited by Dylan Seychell and Alexei Dingli. Cham: Springer, pp. 109-22.

Morell, Mayo Fuster, Enric Senabre Hidalgo, and Enrique Rodríguez. 2020. Goteo.org civic crowdfunding and match-funding data connecting Sustainable Development Goals. Sci Data 7: 132. [CrossRef] [PubMed]

Mourato, Susana, Ece Ozdemiroglu, Tannis Hett, and Giles Atkinson. 2004. Pricing cultural heritage. World Economics 5: 95-113.

Nijkamp, Peter. 2012. Economic Valuation of Cultural Heritage. In The Economics of Uniqueness: Investing in Historic City Cores and Cultural Heritage Assets for Sustainable Development. Edited by Guido Licciardi and Rana Amirtahmasebi. Washington, DC: The World Bank, pp. 75-106.

Nylund, Niklas. 2020. Game Heritage: Digital Games in Museum Collections and Exhibitions. Ph.D. dissertation, Tampere University, Tampere, Finland.

Oomen, Johan, and Lora Aroyo. 2011. Crowdsourcing in the cultural heritage domain: Opportunities and challenges. Paper presented at the 5th International Conference on Communities \& Technologies, Brisbane, Australia, 29 June 2011 - 2 July 2011; New York: Association for Computing Machinery, pp. 138-49.

Pauget, Bertrand, Jean-Michel Tobelem, and Jean-Philippe Bootz. 2020. The future of French museums in 2030. Technological Forecasting and Social Change 162: 120-384. [CrossRef]

RESTAURA. 2019. PPP in Cultural Heritage Projects. Available online: https://www.interreg-central.eu/Content.Node/PPP-inheritage-revitalisation-projects-planning-and-prep-3.pdf (accessed on 28 January 2021).

Roy, Mousumi. 2020. Sustainable Development Strategies: Engineering, Culture and Economics. Oxford: Butterworth-Heinemann.

Rykkja, Anders, Natalia Maehle, Ziaul Haque Munim, and Rotem Shneor. 2020. Crowdfunding in the Cultural Industries. In Advances in Crowdfunding. Edited by Rotem Shneor, Liang Zhao and Bjørn-Tore Flåten. Cham: Palgrave Macmillan, pp. 423-40.

Šebová, Miriam, Oto Hudec Peter Džupka, and Nataša Urbancíková. 2014. Promoting and financing cultural tourism in Europe through European capitals of culture: A case study of Košice, European capital of culture 2013. Amfiteatru Economic Journal 16: $655-71$.

Shneor, Rotem, Liang Zhao, and Bjørn-Tore Flåten. 2020. Introduction: From Fundamentals to Advances in Crowdfunding Research and Practice. In Advances in Crowdfunding. Edited by Rotem Shneor, Liang Zhao and Bjørn-Tore Flåten. Cham: Palgrave Macmillan, pp. 1-18.

Subires, María Deseada López, and Manuel Pedro Rodríguez Bolivar. 2017. Financial Sustainability in Governments. A New Concept and Measure for Meeting New Information Needs. In Financial Sustainability in Public Administration. Edited by Manuel Pedro Rodríguez Bolivar. Granada: Palgrave Macmillan, pp. 3-20.

Suominen, Jaakko, Anna Sivula, and Maria B. Garda. 2018. Incorporating curator, collector and player credibilities. Special issue. Journal of Media Studies and Popular Culture, 174-96. 
Throsby, David. 1999. Cultural capital. Journal of Cultural Economics 23: 3-12. [CrossRef]

UNITO. 2020. Living Document on Financial Instruments and Regulatory Frameworks for the Introduction of Partnership with Private Sector. FINCH Interreg Europe, Version 5. Available online: https://www.interregeurope.eu/fileadmin/user_upload/ tx_tevprojects/library/file_1589466334.pdf (accessed on 28 January 2021).

Van Montfort, Kees, Vinitha Siebers, and Frank J. De Graaf. 2021. Civic Crowdfunding in Local Governments: Variables for Success in the Netherlands? Journal of Risk and Financial Management 14: 8. [CrossRef]

Varbanova, Lidia. 2003. Financing Cultural Practices in South-Eastern Europe. In Policies for Culture Publication Series. Bucharest: ECUMEST Association/European Cultural Foundation, pp. 2-12.

Zhao, Liang, and Rotem Shneor. 2020. Donation Crowdfunding: Principles and Donor Behaviour. In Advances in Crowdfunding. Edited by Rotem Shneor, Liang Zhao and Bjørn-Tore Flåten. Cham: Palgrave Macmillan, pp. 145-60. 